\title{
INISIASI BUDIDAYA PADI HITAM UNTUK PRODUKSI PRODUK PANGAN EKSKLUSIF DI DESA CILELES KECAMATAN JATINANGOR KABUPATEN SUMEDANG
}

\author{
Fiky Yulianto Wicaksono, Yudithia Maxiselly, Aep Wawan Irwan, dan Tati Nurmala \\ Program Studi Agroteknologi Fakultas Pertanian Universitas Padjadjaran \\ E-mail: fiky.yulianto@unpad.ac.id
}

\begin{abstract}
ABSTRAK. Desa Cileles berada di wilayah Kecamatan Jatinangor, Kabupaten Sumedang. Desa Cileles memiliki wilayah seluas $320 \mathrm{Ha}$, dengan fungsi tata guna lahan untuk lahan pertanian sebesar 55\% dan sisanya merupakan lahan pemukiman dan fasilitas umum. Sebagian besar profesi penduduk desa Cileles adalah petani dan buruh tani. Permasalahan pertanian yang ada di desa Cileles adalah petani hanya membudidayakan tanaman yang tidak memiliki nilai ekonomi tinggi. Salah satu solusi untuk memecahkan masalah ketiadaan produk bernilai ekonomi tinggi namun masih bisa dikonsumsi sehari-hari adalah dengan mengenalkan budidaya padi/beras hitam. Padi hitam merupakan padi lokal yang mengandung pigmen antosianin yang paling baik sehingga termasuk ke dalam pangan fungsional. Beras hitam juga memiliki nilai ekonomi yang tinggi. Pengenalan tanaman padi hitam dan teknologi budidayanya di Desa Cileles memiliki tujuan mensosialisasikan tanaman padi hitam di masyarakat agar masyarakat tertarik mengembangkannya. Sosialisasi ini menggunakan metode penyuluhan dan pembuatan demplot partisipatif pada para petani. Keberhasilan metode Pengabdian kepada Masyarakat yang dijalankan dapat diketahui dari kuesioner yang dibagikan pada peserta penyuluhan. Penyuluhan budidaya dan pascapanen padi hitam yang baik disertai pembuatan petak demonstrasi menimbulkan respons yang baik dari petani. Hal ini dapat dilihat dari pengetahuan petani terhadap padi hitam yang meningkat, keinginan masyarakat yang tinggi untuk membudidayakan padi hitam, serta masyarakat antusias untuk memasarkan sendiri produk padi hitam.
\end{abstract}

Kata kunci: Jatinangor, Padi hitam, Pangan fungsional

ABSTRACT. Cileles is a village that located in Jatinangor sub-district, Sumedang regency. The village has 320 ha area, 55\% of that area is agricultural field, and the others are residential land and public facilities. Most of workers are farm laborers and farmers. One of the agriculture problem in this village is the farmers only cultivate low economic value crops. One of problem solving to improve high economic value products but can still be consumed daily is by socialize black rice cultivation. Black rice is local rice which contains anthocyanin pigments, so it is included as functional food. Black rice also has high economic value. The introduction of black rice and its cultivation technology in Cileles Village has the aim to socialize black rice plants in the community so they are interested in developing it. This socialization uses counseling methods and the making of participatory demonstration plots for farmers. Success indicators of this method are described by participant questionnaires. Socialization of agriculture practices and making demonstration plot gave a good response from farmers. This can be seen from the farmers knowledge about black rice, the high desire of the community to cultivate black rice and make their own black rice products.

Key words: Jatinangor, Black rice, Functional food

\section{PENDAHULUAN}

Desa Cileles termasuk ke dalam wilayah Kecamatan Jatinangor, tepatnya berada dibagian utara wilayah kecamatan. Desa Cileles memiliki jarak tempuh sekitar $2 \mathrm{Km}$ dari pusat Kecamatan Jatinangor dan mencakup sebagian wilayah utara kampus Universitas Padjadjaran. Secara topografi, desa Cileles termasuk kedalam klasifikasi wilayah perbukitan karena posisinya yang berada di kaki gunung Manglayang. Desa tersebut terletak 750$850 \mathrm{~m}$ di atas permukaan laut dengan suhu rata-rata harian sebesar $23,3^{\circ} \mathrm{C}$. Desa Cileles memiliki wilayah seluas 320 $\mathrm{Ha}$, dengan fungsi tata guna lahan untuk lahan pertanian sebesar $176 \mathrm{Ha}$ (55\%) dan sisanya merupakan lahan pemukiman dan fasilitas umum. Lahan pertanian terdiri dari lahan basah (sawah) sebesar $58 \mathrm{Ha}$ dan lahan kering (ladang, kebun, tegalan) sebesar $118 \mathrm{Ha}$.

Desa Cileles memiliki jumlah penduduk sebanyak 5.524 jiwa dengan rincian sebanyak 2817 jiwa berjenis kelamin laki-laki dan 2.707 jiwa berjenis kelamin perempuan. Jumlah KK sebanyak 1.868 jiwa dengan rasio kepadatan penduduk per $\mathrm{Km}^{2}$ adalah sebesar 279 jiwa $/ \mathrm{Km}^{2}$. Tata guna lahan desa Cileles yang didominasi lahan pertanian menyebabkan sebagian besar profesi penduduk desa Cileles adalah petani dan buruh tani, walaupun sebagian kecil juga ada di sektor perdagangan, peternakan, dan bangunan (konstruksi). Produk pertanian yang dihasilkan berupa padi dan beberapa palawija, seperti jagung, bawang merah, ubi jalar, ketela pohon, kacang tanah, dll. Padi umumnya ditanam sebagai sumber produksi utama, sementara tanaman lain ditanam sebagai selingan ketika menunggu musim tanam padi dimulai. Di kalangan masyarakat desa Cileles, hasil panen kebanyakan dikonsumsi keluarga sendiri dan sebagai pakan ternak.

Permasalahan pertanian yang ada di desa Cileles adalah petani hanya menanam tanaman yang biasa mereka tanam. Oleh karena itu, kebanyakan tanaman yang ditanam adalah tanaman yang bisa dikonsumsi sehari-hari. Produk hasil tani yang diperoleh pun bukan produk bernilai ekonomi tinggi. Selain itu, sebagian besar penyuluhan pertanian yang dilakukan pemerintah masih dirasakan kurang efektif bagi petani karena tidak berwujud praktek di lapangan, melainkan hanya sekedar penjelasan teori lewat presentasi dan tulisan. Hal ini tentunya menjadi 
hambatan tersendiri bagi petani Desa Cileles karena sebagian dari mereka masih tidak bisa membaca, bahkan buta huruf sepenuhnya.

Salah satu solusi untuk memecahkan masalah ketiadaan produk bernilai ekonomi tinggi namun masih bisa dikonsumsi sehari-hari oleh petani atau keluarga tani adalah dengan mengenalkan budidaya padi/beras hitam. Padi hitam merupakan padi lokal yang mengandung pigmen antosianin yang paling baik dibandingkan dengan jenis padi lain sehingga terlihat berwarna hitam (Suardi \& Ridwan, 2009). Kandungan antosianin dalam beras hitam sekitar 200-400 mg/100g lebih besar dibandingkan dengan beras merah $(0,33-1,39 \mathrm{mg} / 100 \mathrm{~g})$ dan ketan hitam $(109,52$ - 256,61 mg/100g). Kandungan antosianin dalam padi hitam terdapat pada perikarp, aleuron dan endosperm yang berwarna merah-biru-ungu pekat (Purwanto, 2010). Antosianin yang terdapat dalam beras hitam berfungsi sebagai antioksidan yang dapat melindungi tubuh dari radikal bebas sehingga menghambat perkembangan sel kanker dalam tubuh. Selain itu, kandungan antosianin dalam beras hitam dapat mengurangi level kolesterol dan menurunkan risiko diabetes (Guo dkk., 2007 dalam Kushwaha, 2016).

Beras hitam juga memiliki nilai ekonomi yang tinggi. Hal ini dapat dilihat dari harga jual beras hitam yang lebih tinggi dibandingkan dengan beras biasa atau ketan. Gabah padi hitam di tingkat petani dijual dengan harga Rp10.000/kg, di tingkat pengumpul mencapai $\mathrm{Rp} 17.000 / \mathrm{kg}$, di tingkat distributor mencapai Rp30.000/ kg bahkan di tingkat pengecer dapat mencapai Rp58.000/ $\mathrm{kg}$ lebih tinggi daripada gabah padi putih yang hanya dijual antara Rp7.000/kg di tingkat petani, Rp13.000/kg di tingkat pengumpul, Rp16.000/kg di tingkat distributor dan Rp33.000/kg di tingkat pengecer (Stefani, 2016).

Pengenalan tanaman padi hitam dan teknologi budidayanya di Desa Cileles memiliki tujuan mensosialisasikan tanaman padi hitam di masyarakat agar masyarakat tertarik mengembangkannya. Pengenalan tersebut dapat dilakukan dengan cara meningkatkan pemahaman masyarakat mengenai kegunaan tanaman padi hitam, produkproduknya, serta teknik budidayanya. Penanaman padi hitam lokal di masyarakat diharapkan dapat terwujud dan berkelanjutan sehingga dapat meningkatkan penghasilan petani.

\section{METODE}

Sosialisasi tanaman padi hitam dan budidayanya dilakukan di Desa Cileles, Kecamatan Jatinangor, Kabupaten Sumedang, mulai bulan Maret sampai dengan Juli 2018. Kegiatan ini melibatkan petani dan wanita tani karena selain petani, para ibu tani diharapkan nantinya dapat membujuk suaminya untuk membudidayakan tanaman padi hitam. Sosialisasi ini menggunakan metode penyuluhan dan pembuatan demplot partisipatif. Materi penyuluhan merupakan hasil-hasil penelitian yang dirangkum oleh tim dosen. Demplot partisipatif budidaya padi hitam dibuat bersama-sama oleh petani dan diawasi pelaksanaannya oleh tim dosen dan mahasiswa peserta Kuliah Kerja Nyata (KKN).

Materi penyuluhan berisi mengenai:

a. Pengenalan tanaman padi hitam, baik morfologi, kandungan gizi, dan daerah asalnya.

Pengenalan morfologi padi hitam berisi materi mengenai persamaan dan perbedaan antara padi hitam dengan padi biasa dan ketan, baik dari penampilan tanaman di lahan, umur tanaman, maupun hasil panen atau bijinya. Penjelasan kandungan gizi beras hitam berisi berbagai jenis gizi yang membedakannya dengan beras yang lain. Daerah asal, sumber genetik, dan penyebaran tanaman padi hitam di Indonesia juga dijelaskan agar peserta penyuluhan paham bahwa padi hitam dapat tumbuh di Indonesia.

b. Pengenalan harga dan pemasaran beras hitam Pemaparan mengenai harga dan pemasaran beras hitam dimaksudkan agar petani tertarik untuk menanam padi hitam. Beras hitam memiliki nilai jual paling tinggi dibandingkan jenis beras lainnya. Petani dapat memilih jenis pemasaran beras hitam yang sekarang tersedia, baik melalui supermarket atau penjualan online.

c. Teknologi budidaya padi hitam

Teknologi budidaya padi hitam meliputi tahapan sebelum tanam sampai panen. Tahapan tersebut diantaranya adalah pemilihan lahan, persiapan benih, pengolahan lahan, pembuatan persemaian, persiapan tanam, teknologi penanaman, pemeliharaan tanaman (pemupukan, pengendalian organisme pengganggu tanaman, dan manajemen air), dan teknologi panen. Pada materi teknologi budidaya ini juga dijelaskan beberapa hasil penelitian, seperti aplikasi retardan untuk menghambat pertumbuhan tanaman padi hitam sehingga umur panen dapat lebih pendek.

d. Teknologi pascapanen padi hitam

Materi ini berisi teknologi penyimpanan gabah/biji/ benih padi hitam dan pengemasan produk. Materi pascapanen diberikan agar petani mengetahui cara menyimpan atau mengemas gabah/biji/benih padi hitam sehingga dapat tahan lama.

Keberhasilan metode Pengabdian kepada Masyarakat(PKM) yang dijalankan dapat diketahui dari kuesioner yang dibagikan pada peserta penyuluhan. Kuesioner juga berfungsi menampung saran dan kritik dari petani terhadap metode PKM yang telah dijalankan sehingga tim dapat memperbaiki metode pada PKM selanjutnya. Kuesioner dibagikan dalam bentuk pre-test dan post-test. Pre-test berfungsi untuk mengetahui pengetahuan petani sebelum penyuluhan sementara post test berfungsi untuk menilai tingkat keberhasilan penyuluhan. Kuesioner berisi pertanyaan mengenai:

a. Peserta penyuluhan apakah sebelumnya telah 
mengenal padi hitam atau mengkonsumsi beras hitam. Hal ini untuk melihat pengetahuan awal para peserta sebelum penyuluhan.

b. Peserta penyuluhan apakah dapat membedakan antara beras hitam dan ketan hitam. Hal ini untuk mengetahui pengetahuan peserta dalam mengetahui karakteristik produk padi hitam.

c. Peserta penyuluhan apakah mengenal kandungan gizi padi hitam. Hal ini untuk merangsang petani mengembangkan padi hitam yang memiliki nutrisi yang kaya.

d. Peserta penyuluhan apakah sebelumnya pernah menanam padi hitam dan mengenal teknologi budidayanya. Hal ini untuk mengetahui pengetahuan awal peserta dalam mengembangkan penanaman padi hitam.

e. Seberapa besar keinginan petani dalam mengembangkan tanaman padi hitam. Hal ini dapat dilihat dari penambahan penghasilan yang diinginkan, kesulitan yang mungkin ditemukan, dan keinginan memasarkan produk padi hitam secara mandiri. Hal ini untuk mengukur potensi pengembangan padi hitam di desa Cileles.

i. Peserta penyuluhan apakah tertarik dan bersedia memelihara demplot pertanaman gandum yang akan dibuat di lahan petani Desa Cileles. Hal ini untuk melihat animo peserta dalam mengembangkan tanaman gandum di desanya.

Analisis dilakukan pada data yang diperoleh dari kuesioner menggunakan uji statistik deskriptif, seperti ukuran pemusatan dan ukuran penyebaran (Budiarto, 2001).

\section{HASIL DAN PEMBAHASAN}

Inisiasi pengembangan budidaya padi hitam diawali dengan kegiatan penyuluhan. Penyuluhan dilakukan di Fakultas Pertanian, Universitas Padjadjaran, Kabupaten Sumedang. Kegiatan terbagi menjadi beberapa acara, yaitu presentasi materi penyuluhan dari tim PKM, diskusi mengenai materi penyuluhan, pembagian benih padi hitam, dan field trip melihat set penelitian padi hitam di Kebun Percobaan Fakultas Pertanian, Ciparanje, Kabupaten Sumedang. Diskusi, pembagian benih, dan field trip dilakukan agar wawasan peserta penyuluhan lebih luas dan peserta antusias sebelum mereka menanam di lahannya sendiri dan pada demplot.

Kuesioner diisi oleh peserta penyuluhan untuk mengetahui latar belakang petani serta tingkat pemahaman sebelum dan setelah penyuluhan. Sebanyak 34 responden mengisi kuesioner. Umur rata-rata petani responden adalah 47 tahun dengan sebaran umur seperti terlihat pada Gambar 1. Tanaman yang diusahakan petani diantaranya adalah padi, bambu, dan palawija (ketela pohon, jagung, kacang-kacangan, dan ubi jalar). Sebanyak 51\% petani memiliki lahan sendiri, sementara 49\% mengusahakan tanamannya di lahan milik orang lain. Rata-rata luas lahan pertanian yang dimiliki oleh petani adalah 3056 $\mathrm{m}^{2}$ (standar deviasi $1548 \mathrm{~m}^{2}$ ), sebanyak 51\% merupakan lahan sawah, sementara 49\% merupakan lahan non sawah. Standar deviasi kepemilikan luas lahan pertanian yang tinggi (lebih dari 20\%) menandakan bahwa petani memiliki lahan pertanian dengan luas yang sangat beragam (Budiarto, 2001).

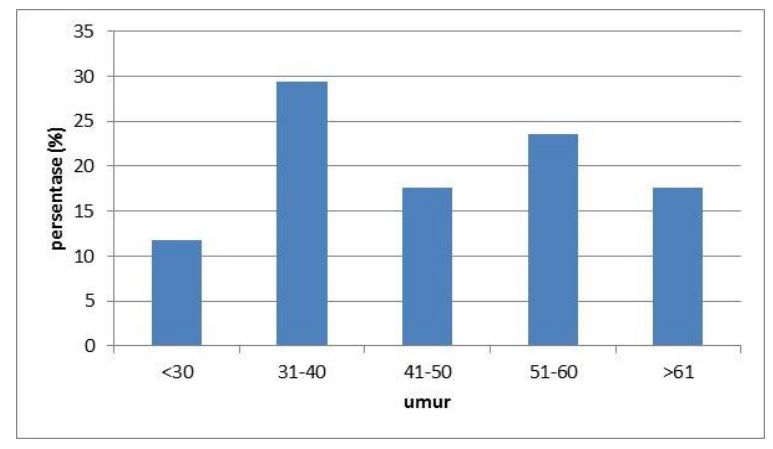

Keterangan: standar deviasi 13,5 tahun

Gambar 1. Grafik Umur Responden

Umur responden lebih dari 35 tahun menunjukkan petani-petani di Desa Cileles bukan petani muda. Davis et. al. (2013) dalam Susilowati (2016) menyebutkan bahwa batas umur petani muda adalah 35 tahun. Umur biasanya berhubungan dengan kualitas pendidikan petani dimana semakin tua semakin rendah pendidikannya (Susilowati, 2016). Umur responden yang semakin tua dapat mempengaruhi tingkat penyerapan teknologi. Oleh karena itu, tim perlu memilih strategi penyuluhan yang tepat agar dapat dipahami oleh petani.

Rata-rata luas lahan petani $\left(3056 \mathrm{~m}^{2}\right)$ masih di bawah luas lahan usahatani yang dibutuhkan untuk mencapai break even point (BEP) usahatani padi, jagung, dan kedelai, yaitu masing-masing sebesar 5100, 4100, dan $4600 \mathrm{~m}^{2}$. Luas lahan petani juga masih di bawah garis batas kemiskinan untuk usahatani padi, jagung, dan kedelai menurut Badan Pusat Statistik, yaitu 6500, 11200, dan $7400 \mathrm{~m}^{2}$ (Susilowati dan Maulana, 2016). Lahan yang sekecil itu harus menjadi pertimbangan bagi strategi penyuluhan, sebab lahan yang sempit memiliki korelasi dengan tingkat kesejahteraan petani (Darwanto, 2005). Oleh karena itu, strategi penyuluhan harus menyinggung pada peningkatan penghasilan petani.

Hasil kuesioner sebelum penyuluhan (pre-test) menunjukkan bahwa 100\% responden belum mengenal morfologi tanaman padi hitam, apalagi mengonsumsi produk padi hitam (beras hitam). Sebanyak 65\% responden dapat membedakan antara beras hitam dengan ketan hitam yang biasa dibuat dengan bubur kacang hijau, namun 35\% masih belum mengenal perbedaannya. Semua responden juga belum mengetahui kandungan gizi pada padi hitam, belum pernah menanam padi hitam, dan belum mengetahui cara membudidayakan padi hitam. 
Meskipun responden masih banyak yang tidak mengetahui mengenai padi hitam, namun responden antusias untuk mengembangkan padi hitam di daerahnya. Responden ingin mengembangkan padi hitam, dengan syarat yaitu pengembangan tanaman padi hitam dapat menambah penghasilannya. Sebanyak $82 \%$ responden ingin mengembangkan padi hitam bila keuntungan padi hitam minimal sama dengan padi biasa. Peningkatan keuntungan yang diharapkan oleh petani berkisar antara $10 \%$ sampai $300 \%$. Sebanyak $88 \%$ dari responden yang tertarik mengembangkan padi hitam menyatakan bila pengembangan padi hitam ternyata sulit, namun dapat menambah penghasilannya, maka mereka tetap akan mengembangkan padi hitam. Sebanyak $75 \%$ responden bahkan siap memasarkan sendiri produk beras hitamnya.

Antusiasme petani terhadap pengembangan padi hitam bila dapat menambah penghasilannya sesuai dengan yang dinyatakan oleh Bunch (2001) dan Wicaksono, et. al. (2018). Bunch (2001) berpendapat bahwa peningkatan pendapatan perorangan merupakan faktor tunggal yang paling menentukan semangat masyarakat dalam melaksanakan ide program yang ditawarkan. Peningkatan keuntungan sebesar 10\% sampai 300\% yang diharapkan oleh petani masih bisa dipenuhi mengingat harga beras hitam dapat mencapai 4 kali lipat dari harga beras biasa di tingkat konsumen. Dengan demikian, petani harus diarahkan untuk membuat merk dari produk hitam yang dihasilkannya serta memasarkannya sendiri agar peningkatan keuntungan tercapai.

Hasil kuesioner setelah penyuluhan (post test) menunjukkan bahwa semua responden akhirnya mengenal morfologi tanaman padi hitam, dapat membedakan beras hitam dan ketan hitam, telah mengetahui kandungan gizi beras hitam, dan tertarik menanam padi hitam. Hal ini menunjukkan bahwa materi penyuluhan dapat diterima dengan baik oleh responden.

Semua responden setelah penyuluhan tertarik membudidayakan padi hitam meskipun umur tanamannya panjang sehingga waktu panennya lama. Kesulitan lain yang dianggap penting oleh responden adalah ketersediaan air, benih, pupuk, dan responden belum mempunyai pengalaman menanam padi hitam. Petani tertarik menanam padi hitam meskipun ada kesulitan-kesulitan tersebut karena melihat kandungan gizi dan harga jual padi hitam yang tinggi. Responden tertarik membudidayakan padi hitam di berbagai tempat, diantaranya adalah pekarangan rumah (menggunakan polibag), sawah, dan ladang/tegalan. Hal ini dapat dijadikan pertimbangan untuk melakukan penelitian teknologi budidaya di tempattempat tersebut. Penggunaan teknologi yang tepat sesuai dengan yang diinginkan oleh petani merupakan hal yang penting. Penggunaan metode yang mudah dipahami dan dilakukan oleh petani akan mempermudah adopsi teknologi (Musyafak dan Ibrahim, 2005).

Antusiasme responden untuk memasarkan sendiri produk padi hitam juga meningkat setelah penyuluhan bila dibandingkan sebelum penyuluhan. Sebanyak 94\% responden bersedia memasarkan sendiri produk padi hitam, meskipun sebanyak 35\% responden menganggap pemasaran sendiri produk padi hitam akan menyulitkan. Antusiasme yang meningkat disebabkan sudah baiknya pemahaman petani terhadap gizi dan harga jual padi hitam. Hal ini sesuai dengan pendapat Hasanuddin (2005), bahwa ketersediaan informasi menentukan tingkat adopsi suatu teknologi oleh masyarakat. Secara menyeluruh, perbandingan pengetahuan dan antusiasme petani sebelum dan setelah penyuluhan disajikan pada Tabel 1 .

Tabel 1. Perbandingan pengetahuan dan antusiasme petani sebelum dan setelah penyuluhan

\begin{tabular}{lcc}
\hline \multirow{2}{*}{ Pengetahuan dan antusiasme petani } & \multicolumn{2}{c}{ Indikator } \\
\cline { 2 - 3 } & $\begin{array}{c}\text { Sebelum } \\
\text { penyuluhan }\end{array}$ & $\begin{array}{c}\text { Sesudah } \\
\text { penyuluhan }\end{array}$ \\
\hline $\begin{array}{l}\text { Pengetahuan morfologi, kandungan } \\
\text { gizi, dan ciri khas tanaman padi }\end{array}$ & $21,7 \%$ & $100 \%$ \\
hitam & & \\
$\begin{array}{l}\text { Keinginan membudidayakan dan } \\
\text { memasarkan padi hitam }\end{array}$ & $78,5 \%$ & $97 \%$ \\
\hline
\end{tabular}

Pembuatan demplot setelah penyuluhan juga mendapatkan respons yang baik dari petani. Hal ini sesuai dengan kuesioner yang dibagikan pada para petani setelah penyuluhan. Sebanyak $88 \%$ petani tertarik untuk memelihara petak demonstrasi budidaya padi hitam.

\section{SIMPULAN}

Penyuluhan budidaya dan pascapanen padi hitam yang baik disertai pembuatan petak demonstrasi menimbulkan respons yang baik dari petani. Hal ini dapat dilihat dari pengetahuan petani terhadap padi hitam yang meningkat, keinginan masyarakat yang tinggi untuk membudidayakan padi hitam, serta masyarakat antusias untuk memasarkan sendiri produk padi hitam.

\section{UCAPAN TERIMAKASIH}

Penulis mengucapkan terimakasih kepada Universitas Padjadjaran yang telah membiayai kegiatan pengabdian kepada masyarakat ini melalui skema KKN PPM Integratif 2018.

\section{DAFTAR PUSTAKA}

Bunch, R. 2001. Dua Tongkol Jagung: Pedoman Pengembangan Pertanian Berpangkal pada Rakyat. Yayasan Obor Indonesia. Jakarta.

Budiarto, Eko. 2001. Biostatistika untuk Kedokteran dan Kesehatan Masyarakat. Penerbit Buku Kedokteran EGC. Jakarta.

Darwanto, D. H. 2005. Ketahanan pangan berbasis produksi dan kesejahteraan petani. Ilmu Pertanian. Vol. 12 (2): 152 - 164. 
Hasanuddin, T. 2005. Adopsi inovasi dalam kegiatan usahatani pada beberapa spesifik sosiobudaya petani di Propinsi Lampung. Jurnal Agrijati. Vol 1 (1).

Kushwaha, U. K..2016. Black Rice. In Black Rice, Hlm. 21-48. Switzerland: Springer International Publishing. Available online at https://doi. org/10.1007/978-3-319-30153-2 (diakses 20 Mei 2017)

Musyafak, A. dan T.M. Ibrahim. 2005. Strategi percepatan adopsi dan difusi inovasi pertanian mendukung prima tani. J. Anal. Kebij. Pert. Vol. 3 (1) : $20-37$

Purwanto, E. 2010. Manfaat beras hitam. Available online at https://uns.ac.id/id/uns-update/ini-dia-berbagaimanfaat-beras-hitam.html (diakses 20 Mei 2017)

Stefani, E. 2016. Strategi pengembangan usaha beras hitam pada asosiasi tani organik sawangan di Kabupaten Magelang. Tesis. Sekolah Pascasarjana Institut Pertanian Bogor, Bogor
Suardi, D., dan Ridwan, I. 2009. Beras hitam, pangan berkhasiat yang belum populer. Warta Penelitian dan Pengembangan Pertanian. 31(2) : 9-10.

Susilowati, S. H. 2016. Fenomena penuaan petani dan berkurangnya tenaga kerja muda serta implikasinya bagi kebijakan pembangunan pertanian. Forum Penelitian Agro Ekonomi. Vol. 34 (1): 35 - 55

Susilowati, S. H. dan M. Maulana. 2016. Luas Lahan Usaha Tani dan Kesejateraan Petani: Eksistensi Petani Gurem dan Urgensi Kebijakan Reforma Agraria. Analisis Kebijakan Pertanian, 10 (1): 1730.

Wicaksono, F.Y., Y. Maxiselly, T. Nurmala, P. U. Suherman, A. Fauzan, dan A. M. Nurdin. Respons masyarakat terhadap pengenalan tanaman gandum dan produk-produknya di desa Arjasari kecamatan Arjasari kabupaten Bandung. Dharmakarya. Vol. 7 (1): $32-37$. 